\title{
An Assessment of Kenyan Level Four Hospitals Technological Infrastructure for Telemedicine Adoption
}

\author{
Karisa K. Randu, Alice Nambiro, Juma Kilwake
}

\begin{abstract}
There being most of Kenya's Health professionals leaving the country for more lucrative jobs abroad which results in a severe shortage of medical workers across the country, this gets even worse when it comes to the level four hospitals. This consequently leads the level four hospitals to offer a limited treatment services. By adopting telemedicine, nurses who are employed by the hospital to nurse some of the patients can get assistance from a health care professional who can guide through video conferencing, moreover provides a platform that brings more treatment services to hospitals. Therefore the paper presents an assessment of the level four hospitals' technological infrastructure for telemedicine adoption. Questionnaires were used to collect quantitative data and structured interviews were used to collect qualitative data. The quantitative data obtained was analyzed using descriptive statistical techniques and results were presented using frequency tables, triangulation was used to back up the quantitative data from the qualitative data obtained. The study found out that the level four hospitals possesses just a part of the telemedicine technological infrastructure that can be used to adopt telemedicine at an infancy level. The study recommends that all the computers in the level four hospitals be equipped with a web camera, improve the internet bandwidth, consider installing VOIP software on their computers that are more reliable with better call quality and finally they should consider buying larger LCD screens.
\end{abstract}

Index Terms-Health Care, Technological infrastructure, Telemedicine, Telemedicine Adoption.

\section{INTRODUCTION}

Telemedicine is characterized as the use of telecommunications and information technology to provide patients in different locations with clinical health care [1]. According to [3] telemedicine provides a distance elimination barrier and can improve heavily the access to medical services of which would often not be consistently available for distant rural communities. Usually It is used to save lives that are in critical care and also emergency situations.

Telemedicine for long has been a medical puzzle for quite a number of years, the good thing is that the depth and variety of services being cared for has grown drastically for this time, partnered with "rural health", telemedicine is emerging as an integral part of general health services to all populated areas.

Karisa K. Randu, Department of Information Technology, Kibabii University, Bungoma, Kenya

Dr Alice Nambiro Wechuli, PhD, Department of Information Technology, Kibabii University, Bungoma, Kenya,

Mr Juma H. Kilwake, Department of Computer Science, Kibabii University, Bungoma, Kenya
A reason for it is because of the broad scope of services that entails the term [3].

In general, "it is the provision of consultation and education in health care using telecommunications networks to transmit knowledge". Telemedicine provides facilities such as hospital consultations, specialist referral services, mobile nurse triage, online patient care, medical health data and education under these guidelines [8].

The benefits of telemedicine are; first, "its cost effective", Several research findings indicate that telemedicine is one of the most cost-effective ways to deliver health care.

An example is an e-ICU program in South Dakota that saved more than $\$ 1.2$ million in patient transfer costs over just 30 months for eight hospitals [8].

Second "It effectively handles chronic diseases, i.e. long-term care and use of multiple specialists is needed for chronic conditions such as diabetes, congestive heart failure and obstructive pulmonary disease, thereby telemedicine can come in to reduce the cost" [3].

Third, "Improve elderly, home-bound and physically disabled patients' health care"; the use of telemedicine to reduce the frequency of doctor's office and hospital emergency room visits can contribute to greater elderly and home-based patients' comfort and compliance. By reducing the frequency of remote monitoring visits and the sharing of e-mail information, timely patient intervention can occur before acute care is required [3].

Fourth, "Empowers patients with respect to their own health"; increasing patients' duty to take their medications and report to their doctor(s) basic health metrics by an incentive for patients and caregivers to play a greater role in their own treatment with the help of telemedicine. Patients are more likely to comply with treatment guidelines by providing the patient the ability to see clearly the association between adherence to the treatment regimen and progress in health, leading to a quicker recovery [3].

Fifth; "Improve the health of the community"; electronic sharing of photographs and videos, a feature of telemedicine, makes it easier for public health providers to share information on a rare or uncommon health condition, to help assess a population's chronic illness or to solve a public health problem such as pandemic flu or anthrax.

Since a great deal has already been published about the possible importance of telemedicine for Africa, there is actually little uptake. This is because there are many challenges with least being the lack of doctors and also the unfortunate reality that there is an additional phase into the 
routine of clinical workflow with most telemedicine operations, which adds strain to the doctors and nurses who are already overworked. Telemedicine includes information and communication technology, the capability to actually use the infrastructure, a comparatively more reliable electricity supply, as well as the ability of individuals to actually sustain and facilitate the infrastructure [5].

Previous studies in Kenya show that telemedicine is adapted to a little extent in areas such as doctor consultations, radiology and pharmacy laboratory. In other hospital area services like dermatology, dental, surgery, cardiology, physiotherapy, ophthalmology etc., telemedicine was not adopted yet. generally, the extent at which adoption of telemedicine is in hospitals is low [7].

Internet access, on the other hand, is also increasing so quickly: through laptops as well as desktop computers, and also through mobile phones. Finding ways to efficiently exploit online medical data for these limited and more costly physicians, together with nurses, decision support resources can be crucial to enhancing access for resource-constrained countries to quality health care such as Kenya and everywhere. AMPATHs' machine generated alerts in the electronic health record systems are some examples of successful implementations of e-Health. This has demonstrated that care for developed nations has increased [4].

Reference [2] conclude that Kenya's health system is one that is extremely unequal and that policies aimed at fostering equality and addressing the needs of the poor and disadvantaged have not been effective at all. Yes, there is some progress in addressing equity issues, but universal coverage can not be achieved until a structural approach to health financing reforms has been implemented by the government. A larger health system aimed at fairness and efficiency must drive this strategy.

\section{STATEMENT OF THE PROBLEM}

One of the big challenges in the country is lack of adequate health care professionals who are specialized in the treatment of a disease or suffering of a patient. This gets even worse when it comes to the hospitals which are located in the sub urban areas due to that most likely many of the qualified health care professionals are located in the urban hospital leaving the sub-urban hospitals with more less specialized health care professionals. According to [6], he states that many health care professionals leave Kenya to find more lucrative posts abroad, Ultimately, this results in a severe shortage of medical workers across the country. Kenya only has a single doctor and only 12 nurses or midwives for every 10,000 residents [9].

This is indeed not a pleasing ratio. All together this results in the level four hospitals in Kenya lacking specialized doctors for treating each kind of a disease therefore they are being forced to employ nurses who actually come in to assist in treatment of the disease. Therefore, by adopting telemedicine, nurses who are employed by the hospital to nurse some of the patients will get assistance from a health care professional who can guide through video conferencing or a telephone call.
The paper intends to assess the technological infrastructure for Kenyan level four hospitals so as to provide an awareness of the possibility for adoption of telemedicine in these hospitals which in turn will yield more treatment services being offered.

\section{MATERIALS AND METHODS}

The researcher narrowed down the geographical scope of the topic to the western region of Kenya, the choice of this region was arrived at due to the similar characteristics that the region inhibits compared to the rest, therefore it was assumed that the results obtained can be generalized. The researcher determined the targeted population and used a formula for calculating simplified sample size for proportion in order to determine the sample frame and further used a random number table to identify the hospitals to collect the data from. The researcher established the target population for the respondents and used a formula for calculating simplified sample size for proportion to get the sample frame of the respondents. Questionnaires and interviews which were based on the objective assessment of technological infrastructure in level four hospitals were prepared and a survey was conducted in order to obtain the data required. The quantitative data data obtained was analyzed and results were presented on frequency tables. The qualitative data obtained was used triangulated in order to confirm the quantitative data.

\section{TECHNOLOGICAL INFRASTRUCTURE}

Table 1 reports frequencies of the respondents in line with the questions from the questionnaire. A five-point likert scale was used on a scale of 1= Strongly Disagree, 2=Disagree, 3=Neither Agree or Disagree, 4= Agree 5= Strongly Agree.

Table 2 shows a summary of the keywords that emerged from the interviews, these keywords were used to triangulate the results obtained from the quantitative data.

With regards to the question about enough number of computers in the hospitals, $39.45 \%$ disagreed, $33.03 \%$ were neutral, $20.18 \%$ agreed, $4.59 \%$ strongly disagreed and $2.75 \%$ strongly agreed. The study can confirm the validity of this data by referring to the interviews table. The keywords emerged were not enough and almost sufficient, this implies that the quantitative data obtained was almost right with most of the respondents disagreeing.

The processing power of computers responses were as follows, $66.05 \%$ were neutral, $18.35 \%$ agreed, $8.26 \%$ disagreed, 4.59 strongly agreed and $2.75 \%$ strongly disagreed.

On server computers $80.73 \%$ of the responses were neutral, $8.26 \%$ disagreed, $7.34 \%$ agreed, $2.75 \%$ strongly agreed and $0.92 \%$ strongly disagreed. 
Table I: Technological Infrastructure responses

\begin{tabular}{|c|c|c|c|c|c|c|}
\hline & Strongly Agree $\%$ & Agree $\%$ & Neutral \% & $\begin{array}{l}\text { Disagree } \\
\%\end{array}$ & \multicolumn{2}{|c|}{$\begin{array}{l}\text { Strongly Disagree Total } \\
\%\end{array}$} \\
\hline Number of Computers & 2.75 & 20.18 & 33.03 & 39.45 & 4.59 & 100 \\
\hline Processing Power of Computers & 4.59 & 18.35 & 66.05 & 8.26 & 2.75 & 100 \\
\hline Server Computers & 2.75 & 7.34 & 80.73 & 8.26 & 0.92 & 100 \\
\hline Computer Web Camera & 0 & 2.75 & 0 & 56.88 & 40.37 & 100 \\
\hline Computer LAN & 58.72 & 22.02 & 13.76 & 5.5 & 0 & 100 \\
\hline Large LCD Screen & 0 & 2.75 & 71.56 & 15.6 & 10.09 & 100 \\
\hline Internet Speeds & 0.92 & 31.19 & 3.67 & 35.78 & 28.44 & 100 \\
\hline VOIP Software & 0 & 44.95 & 6.42 & 44.04 & 4.59 & 100 \\
\hline Reliability and Quality of VOIP & 4.59 & 8.26 & 33.94 & 40.37 & 12.84 & 100 \\
\hline Reliability and Quality of Desk P & 7.34 & 19.27 & 52.29 & 11.93 & 9.17 & 100 \\
\hline
\end{tabular}

Availability of Webcam for the computer's responses were as follows, $56.88 \%$ disagreed, $40.37 \%$ strongly disagreed, $2.75 \%$ agreed and there were no responses on strongly agree and neutral.

Table II: Technological Infrastructure Interview Summary

\begin{tabular}{ll}
\hline Theme & Keywords Emerged \\
\hline Level of ICT deployment & Not bad, almost good, adopted, moving well
\end{tabular}

Number of computers available

Web Cameras

Computer network (LAN)

Computer monitors

Internet bandwidth

VOIP applications

reliability and quality of service of VOIP
Not enough, almost sufficient, ratio 1:3,

Not many, most luck, ratio $1: 10$, just a few, countable

Connected, available, Yes

Not that big, not suitable, not pleasing resolution

Somehow fast, not satisfying at times, not classic, unreliable

Not sure, somehow available, no demand

Affected by internet, very poor, at times pleasing, not bad, slow communication

reliability and Good, reliable, instant response, rarely be confirmed by the interviews conducted when keywords quality of service of has noise

\section{Desk Phone}

The disagreement of computers lucking web cameras can be backed by the interviews when the study found the most keywords that emerged were Not many, most luck, ratio 1:10, just a few, countable.

Computer LAN responses were $58.72 \%$ strongly agree, $22.02 \%$ agree, $13.76 \%$ were neutral, $5.5 \%$ disagreed and no responses were there on strongly disagree. These results can

\section{like Connected, available, and Yes emerged.}

For large LCD screens suitable for video conferencing, $71.56 \%$ were neutral, $15.6 \%$ disagreed, $10.09 \%$ strongly disagreed, $2.75 \%$ agreed and none strongly agreed. These results can be confirmed from the interviews conducted when keywords that emerged were like Not that big, not suitable, not pleasing.

Internet speeds responses were $31.19 \%$ agree, $28.44 \%$ strongly disagree, $35.78 \%$ disagree, $0.92 \%$ strongly agree and 
$3.67 \%$ of the responses were neutral. These results can be confirmed from the interview when keywords like Somehow fast, not satisfying at times, not classing, unreliable emerged.

Availability of VOIP software for the computers responses were as follows, $44.95 \%$ agreed, $44.04 \%$ disagreed, $6.42 \%$ were neutral, $4.59 \%$ strongly disagreed and none had a response on strongly agree. These results can be confirmed that they do correlate with the data from the interviews when keywords like Not sure, somehow available, no demand emerged.

The reliability and quality of VOIP software responses were $40.37 \%$ disagree, $33.94 \%$ were neutral, $12.84 \%$ were strongly disagree, $8.26 \%$ agree and $4.59 \%$ strongly agreed. These results can be confirmed from the interviews held when keywords, affected by the internet, very poor, at times pleasing, not bad, slow communication emerged from the interviews.

Reliability and quality of desk phone calls responses were $52.29 \%$ neutral, $19.27 \%$ agree, $11.93 \%$ disagree, $9.17 \%$ strongly disagree and $7.34 \%$ strongly agree. These results can be confirmed that they represent the true picture when keywords like Good, reliable, instant response, little background noise.

\section{RESULTS AND DISCUSSION}

A summary of the responses for the assessment of the technological infrastructure were presented on table 3 reporting the mean, median and the standard deviation.

Table III: Technological Infrastructure Assessment

\begin{tabular}{llll}
\hline & Median & Mean & Std Deviation \\
\hline Number of Computers & 3 & 2.77 & 0.92 \\
Processing Power of Computers & 3 & 3.14 & 0.74 \\
Server Computers & 3 & 3.03 & 0.55 \\
Computer Web Camera & 2 & 1.65 & 0.63 \\
Computer LAN & 5 & 4.34 & 0.92 \\
Large LCD Screen & 3 & 2.67 & 0.69 \\
Internet Speeds & 2 & 2.4 & 1.23 \\
VOIP Software & 3 & 2.92 & 1.04 \\
Reliability and Quality of VOIP & 2 & 2.51 & 0.98
\end{tabular}

possesses just a part of the telemedicine technological infrastructure that can be used to adopt telemedicine at an

The findings from the assessment showed that Computers LAN availability was ranked the highest at a mean of 4.34 and a standard deviation of 0.92 , therefore respondents strongly agreed that the computer LAN is readily available in the hospitals. Second ranked was the processing power of the computers at a mean of 3.14 and a standard deviation of 0.74 , third ranked infrastructure was reliability and quality of desk phone calls at a mean of 3.04 and a standard deviation of 0.99 , fourth ranked infrastructure was server computers at a mean of 3.03 and a standard deviation of 0.55 , fifth ranked was VOIP software at a mean of 2.92 and a standard deviation of 1.04, sixth ranked was the amount of computers in the hospital at a mean of 2.77 and a standard deviation of 0.92 , Seventh ranked infrastructure was Large LCD screens at a mean of 2.67 and a standard deviation of 0.69 , Number eight was the reliability and quality of VOIP software installed in the computers at a mean of 2.51 and a standard deviation of 0.98 , Ninth was Internet speeds at a mean of 2.4 and Last ranked infrastructure was computer web cameras at a mean of 1.65 and a standard deviation of 0.63 .

\section{CONCLUSION AND RECOMMENDATION}

According to the responses obtained from the field by the researcher the study can make the following conclusions. The study reached its objective assessing the technological infrastructure whereby it found out that the level four hospital infancy level. This was attributed by the availability of LAN, better processing power of computers and desk phones calls being reliable with good quality.

According to the findings of the study, it has the following recommendation to the level four hospitals;

i. The study recommends that all the computers in the hospitals should be equipped with a web camera because when it comes to real time communications then the computers are considered and the web camera is indeed an important hardware that a computer should not miss out at all.

ii. Improve the internet bandwidth.

iii. Consider installing VOIP software on there computers that are more reliable with better call quality

iv. Consider buying larger LCD screens.

v. Consider increasing the number of computers in the hospitals.

\section{REFERENCES}

[1] Bajpai, M. (2012), "Telemedicine: A Review". WebmedCentral PUBLIC HEALTH , 6.

[2] Chuma, J., \& Okungu, V. (2011), "Viewing the Kenyan health system through an equity lens: implications for universal coverage". International journal for equity in health, 10(1), 1-14.

[3] Hein, M. A. (2013), "Telemedicine: An Important Force in the Transformation of Healthcare".

[4] Kilwake Juma, Matoke Nahason, Waliaro Apollo. (2012), "Current Status of E-Health in Kenya and Emerging Global Research Trends". esjournals, 5 . 
[5] Mars, M. (2013), "Telemedicine and Advances in Urban and Rural Healthcare Delivery in Africa".

[6] Naicker, S., Plange-Rhule, J., Tutt, R. C., \& Eastwood, J. B. (2009), "Shortage of healthcare workers in developing countries--Africa. Ethnicity \& disease", $\quad$ 19(1), 60.

[7] Shikuku, S. (2013), "Adoption of telemedicine in hospitals in Nairobi County".

[8] TraigeLogic, G. (2013). "Telemedicine in the U.S.:A Review of Barriers \& Benefits". Retrieved 9 14, 2015, from http://triagelogic.com: http://triagelogic.com//wp-content/uploads/files2/blogfiles/Blog-Tele medicine_8-

[9] World Health Organization. (2016)," Global report on urban health: equitable healthier cities for sustainable development".

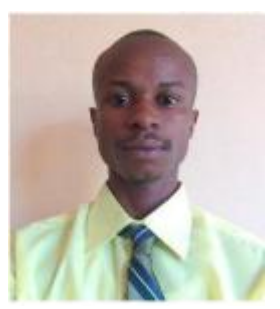

Mr Karisa Randu obtained his Bachelors Degree of Science in Computer Science from Busoga University, Uganda. He is a part time instructor at Kibabii University, Kenya. He has contributed to academic conferences. He has special addiction to algorithms and artificial Intelligence.

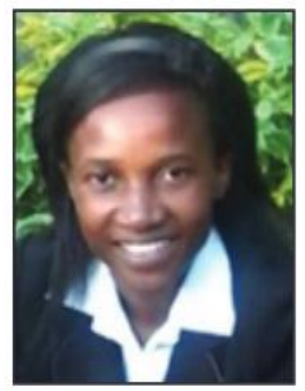

Dr. Alice Nambiro Wechuli received the Bachelor of Science degree in Computer Science from Masinde Muliro University of Science and Technology, Master of Science degree in Information Technology from the same University and Doctor of Philosophy degree in Information Technology from Kibabii University. She is a lecturer in the Department of Information Technology at Kibabii University, Kenya. She is also an in-charge in the directorate of Open, Distance and Electronic Learning in Kibabii University. She has published several high quality papers in peer reviewed journals. She has also attended and contributed at academic conferences. Her research interests include data and information management and system security. She is a member of the International Association of Engineers (IAENG).

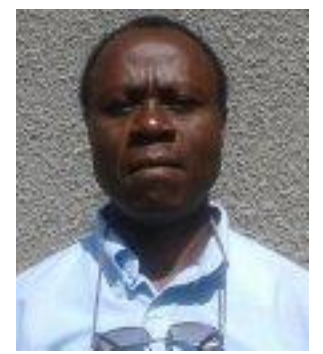

Mr Juma Kilwake is Senior Lecturer in the department of Computer Science of Kibabii University with research interests in the areas of Algorithms, Programming Languages, Data Science and Health Informatics, 